\title{
The Effects of Whole Body Vibration on Body Composition and Lipid Profile in Healthy Young Adults
}

\author{
ELENA IOANA ICONARU ${ }^{1}$, MONICA MARILENA TANTU ${ }^{1}$, MARIANA IONELA TUDOR ${ }^{1}$, \\ MANUELA MIHAELA CIUCUREL ${ }^{2}$, LUMINITA GEORGESCU ${ }^{1}$, ALINA PAUNESCU ${ }^{1 *}$, CAMELIA NICOLAE ${ }^{3}$, \\ FLORENTINA CRISTINA PLESA ${ }^{4}$, CARMEN ADELLA SIRBU ${ }^{4}$, MAGDALENA DIACONU ${ }^{5}$, ALINA BISOC ${ }^{6}$, \\ CONSTANTIN CIUCUREL ${ }^{1}$ \\ ${ }^{1}$ University of Pitesti, Faculty of Sciences, Physical Education and Informatics, 1 Targu din Vale Str., 110040, Pitesti, Romania \\ ${ }^{2}$ University of Pitesti, Faculty of Education, Social Sciences and Psychology, 1 Targu din Vale Str., 110040, Pitesti, Romania \\ ${ }^{3}$ Carol Davila University of Medicine and Pharmacy, 8 Eroii Sanitari Blvd., 050474, Bucharest, Romania \\ ${ }^{4}$ Titu Maiorescu University of Bucharest, Faculty of Medicine, 22 Dambovnicului Str., 040441, Bucharest, Romania \\ ${ }^{5}$ University of Medicine and Pharmacy Craiova, 2 Petru Rares Str., 200349, Craiova, Romania \\ ${ }^{6}$ Transilvania University of Brasov, Faculty of Medicine, 29 Eroilor Blvd., 500036, Brasov, Romania
}

\begin{abstract}
The aim of this study was to determine the physiological and biochemical effects of chronic exposure to whole body vibration on the lipid metabolism in 20 healthy young adults (mean age 23.6 \pm 2.33 years). Each subject was exposed 3 times per week for a total of 6 weeks, in sessions of 15 minutes, at diagonal stimuli, at $25 \mathrm{~Hz}$, on a vibration platform. The protocol had a positive impact on the subjects' body composition and serum lipid profile, with significant effects on lowering weight, body mass index, body fat percentage, total cholesterol and low-density lipoprotein-cholesterol $(p<0.017)$.
\end{abstract}

Keywords: whole body vibration, percent body fat, serum lipids, young people

Body composition is an anthropometric indicator well correlated with direct chemical analysis commonly used in clinical practice to assess the nutritional status of the individual, but also the health and quality of life [1]. In clinical practice, conventional bioelectrical impedance analysis (BIA) is used to determine body composition. The bioelectrical properties of the tissue can be used to predict the total body water and from that the body fat mass, using regression equations [2]. The main parameter investigated by this method is fat mass, total body fat or percent body fat (PBF), which directly reflects the functioning of the lipid metabolism. From the biochemical point of view, important correlations have been established between the percentage of body lipids and the serum levels of the lipid fractions separated by laboratory methods (serum lipid profiles - SLP). Thus, by determining PBF through BIA, predictions can be made on total cholesterol (TC), low-density lipoprotein (LDL), high-density lipoprotein - HDL and triglycerides (TG) [3]. Therefore, to evaluate the lipid metabolic status, it is recommended to corroborate the anthropometric data obtained by analysing the body composition with those of the determinations of blood biochemical parameters, especially in obese patients [4].

Given the epidemiological importance of obesity and its associated metabolic disorders, there is currently an increased interest in validating therapeutic interventions with proven clinical efficiency for this type of pathology. The incidence of stroke is increasing in adolescents and young adults. Currently, $90 \%$ of all strokes can be prevented by influencing modifiable risk factors. Of these, body weight, body mass index (BMI), and lipid profile with abnormal values represent such factors [5,6]. For this reason, the use of the therapeutic effects of vibrations seems to be a promising solution. Mechanical vibrations have wide applicability in medical practice, especially in the form of vibration therapy in the expanding field of regenerative medicine, in conjunction with tissue engineering [7]. A widespread variant of vibration therapy is that of whole body vibration (WBV) exposure, in the form of different protocols such as duration, frequency (low, medium, high) and/or direction of the stimuli (horizontal, vertical, angular). Practically, WBV programs have been clinically validated in different domains, from performance to health, based on localized or global physiological effects. [8]. From a biochemical point of view, the effects of WBV on living tissues are attractive in terms of therapeutic efficacy, although there are some scientific controversies on this topic. Thus, at least in some animal studies (in mice), it appears that WBV training prevents senescence-associated biochemical and pathological alterations [9].

Based on the above considerations, we set as the objective of the research the determination of the physiological and biochemical effects of the chronic exposure to WBV on the lipid metabolism in healthy young adults, by investigating the changes in the BFP and SLP level.

*email: alina_paunescu@yahoo.com, Phone:004-0745-135095

REV.CHIM.(Bucharest) $70 \diamond$ no. $12 \downarrow 2019$
All authors have equal contribution. http://www.revistadechimie.ro 


\section{Experimental part}

Twenty healthy young adults (mean age $23.6 \pm 2.33$ years, mean height $170.61 \pm 9.25 \mathrm{~cm}$, sex ratio $1 / 1$ ) participated in this interventional before-and-after study as volunteers and completed the experimental conditions. To establish the criteria for inclusion and exclusion of the subjects in the experimental group, we used specialized psychological support. Thus, we selected healthy, normal-weight young subjects (21-25 years old), without present morbidity (diabetes, especially with complications, oncological disease) [10-13], with stable eating patterns, without a history of bulimia, anorexia, recent diets or other psychological disorders that interfere with the nutritional status. Also, only subjects who showed compliance with maintaining the lifestyle during the experiment in terms of nutrition, physical activity regime, and exposure to daily stress were included. The general recommendations were to maintain the diet and the physical activity regime in the manner to which the subject is accustomed.

We investigated the effects of repeated exposure at WBV on BFP and SLP in the group of subjects. All the participants underwent three sessions per week on nonconsecutive days for a total of 6 weeks of 15 minutes WBV exposure to diagonal stimuli, at $25 \mathrm{~Hz}$, on a vibration platform (SALUSSSTAR® Innoplate platform, designed by Saluto, Maxline Produkt, Design $\mathrm{GmbH}$, Austria). The platform can generate mechanical vibrations (vertical or diagonal) at different frequencies (15, 25 or $35 \mathrm{~Hz}$ ), with variable amplitude from $0.5 \mathrm{~mm}$ in the centre of the platform to $4 \mathrm{~mm}$ in its outer parts [14]. Each participant was placed in orthostatic position in the centre of the platform during the WBV exposure, with the plants slightly diverging, with palmar support on the holding bars. We opted for 15-minute repeated exposure sessions at diagonal stimuli at $25 \mathrm{~Hz}$ starting from the reported WBV effects on reducing fat mass in the adult general population [15]. Our protocol is original and has no risk for the study participants' health and safety.

The recorded parameters in the experimental group were body weight (W), BMI, BFP and SLP (TC, LDL, HDL and TG). BMI was calculated as $\mathrm{W}$ (in $\mathrm{kg}$ ) divided by height $\left(\mathrm{H}\right.$, in $\mathrm{m}$ ) squared $\left(\mathrm{kg} / \mathrm{m}^{2}\right)$. W and $\mathrm{H}$ were determined according to standard procedures with a portable digital scale (Omron HN-286, Omron Corporation, Kyoto, Japan) and a portable stadiometer (Seca 213, Seca GmbH \& Co. Kg, Hamburg, Germany). We made 3 sets of data gathering: initial testing (T1) before the first WBV session, second testing (T2) after 3 weeks of WBV exposure and final testing (T3) after the last session of WBV, after 6 weeks.

BFP was estimated with bioelectrical impedance analysis using the Omron body fat monitor, model HBF 306, Omron Healthcare Co., Ltd. Dalian, China. The device has good references for clinical use and provides results similar to the dualenergy X-ray absorptiometry (DEXA) in the assessment of BFP [16]. The BFP is measured with the device placed in the hands, based on the electric resistance and personal data such as height, weight, age, and gender. According to producer's instructions, the subjects were placed in orthostatic position, with both feet slightly apart and with both arms straight out, at a 90-degree angle to the body, the hands gripping the electrodes. During the measurement, no movements were allowed. All measurements were performed in the early morning, between 8 and 10 a.m., after an overnight fast (for at least $8 \mathrm{~h}$ ) because food or beverage consumption may affect the values of BFP [17].

SLP parameters were measured from fasting blood samples, with a LipidPro Testing System (infopia Co., Ltd, Korea), which offers a reliable alternative to conventional laboratory methods for rapid lipid determination [18]. For TC, HDL and TG the device uses the spectroscopy method (the principle of enzyme chromophoric reaction) and for calculation of LDL the Friedewald's formula: LDL $=\mathrm{TC}-\mathrm{HDL}-(\mathrm{TG} / 5)$ [19].

For the statistical analysis of data, we used IBM SPSS for Windows 20.0. The analysis implied descriptive statistics for determining of mean, median and standard deviation (SD) and inferential statistics: the Shapiro-Wilk test for checking the normality of the distribution of data, the Friedman test, and the Wilcoxon signed-rank test for post-hoc paired comparison, with Bonferroni-corrected alpha level for three pairwise comparisons. Therefore, the dependent variables were the parameters W, BMI, BFP, TC, LDL, HDL, and TG, whilst the independent variable was time, with three related groups: before the WBV exposure - T1, after 3 weeks of WBV exposure - T2 and after 6 weeks of WBV exposure - T3.

\section{Results and discussions}

Following the anthropometric evaluations, we found that all subjects recorded values within normal limits, depending on age and sex for W, BMI, and BFP. For comparison, we considered the normal range for BMI between 18.5-24.9 [20], and BFP between $10-20 \%$ for men and 20-30\% for women, according to the manufacturer's manual of the body fat monitor. Regarding the SLP, 3 subjects (15\%) had initially some lipid parameters (TC, LDL, HDL and / or TG), in the borderline range. For 2 of them (10\%), the borderline values, although slightly lower, persisted at the final recording. As normal reference values for SLP, we considered the current international recommendations according to age and sex [21]. 
From Table 1 it is observed that all parameters registered a slight improvement between the three tests (decreases for the mean values of $\mathrm{W}, \mathrm{BMI}, \mathrm{BFP}, \mathrm{TC}, \mathrm{LDL}$, and TG and increase for HDL respectively).

Table 1

STATISTIC INDICATORS FOR INVESTIGATED PARAMETERS IN THE EXPERIMENTAL GROUP

\begin{tabular}{|l|l|l|l|l|l|l|l|l|}
\hline & Variable & $\begin{array}{l}\text { W } \\
(\mathrm{kg})\end{array}$ & $\begin{array}{l}\text { BMI } \\
\left(\mathrm{kg} / \mathrm{m}^{2}\right)\end{array}$ & $\begin{array}{l}\text { BFP } \\
(\%)\end{array}$ & $\begin{array}{l}\text { TC } \\
(\mathrm{mg} \%)\end{array}$ & $\begin{array}{l}\text { LDL } \\
(\mathrm{mg} \%)\end{array}$ & $\begin{array}{l}\text { HDL } \\
(\mathrm{mg} \%)\end{array}$ & $\begin{array}{l}\text { TG } \\
(\mathrm{mg} \%)\end{array}$ \\
\hline \multirow{4}{*}{ T1 } & Mean & 60.98 & 20.83 & 18.39 & 176.30 & 96.97 & 51.70 & 138.15 \\
\cline { 2 - 9 } & Median & 60.90 & 20.55 & 18.35 & 169.50 & 88.50 & 51.50 & 136.50 \\
\cline { 2 - 9 } & SD & 9.01 & 1.41 & 5.13 & 22.59 & 25.41 & 8.15 & 8.96 \\
\hline \multirow{3}{*}{ T2 } & Mean & 60.88 & 20.79 & 18.34 & 174.15 & 94.55 & 52.30 & 137.30 \\
\cline { 2 - 9 } & Median & 60.90 & 20.52 & 18.35 & 167.00 & 87.50 & 52.00 & 135.50 \\
\cline { 2 - 9 } & SD & 9.15 & 1.49 & 5.20 & 22.13 & 24.62 & 7.55 & 9.92 \\
\hline \multirow{3}{*}{ T3 } & Mean & 60.39 & 20.63 & 18.21 & 171.75 & 91.80 & 52.60 & 136.75 \\
\cline { 2 - 9 } & Median & 60.45 & 20.37 & 18.15 & 165.00 & 85.00 & 51.00 & 134.50 \\
\cline { 2 - 9 } & SD & 9.04 & 1.46 & 5.11 & 21.86 & 24.78 & 7.77 & 9.50 \\
\hline
\end{tabular}

Legend: $\mathrm{W}=$ weight; $\mathrm{BMI}=$ body mass index; BFP = body fat percentage; TC = total cholesterol;

$\mathrm{LDL}=$ low-density lipoprotein; HDL = high-density lipoprotein; TG = triglycerides.

Next, the data were analysed for normality through the Shapiro Wilk test and we found a non-normal distribution of all variables. Because the assumptions for ANOVA with repeated measures are not met, we processed the series of data with the non-parametric Friedman test with three repeated measures (Table 2) and we used the median for comparison between related groups.

Table 2

THE STATISTICALLY SIGNIFICANT DIFFERENCE BETWEEN THE MEAN RANKS OF THE RELATED GROUPS USING THE FRIEDMAN TEST $(\mathrm{N}=20, \mathrm{df}=2)$

\begin{tabular}{|l|l|l|l|l|l|l|l|}
\hline Test statistics & W & BMI & BFP & TC & LDL & HDL & TG \\
\hline Chi-square & 20.10 & 20.10 & 11.38 & 39.07 & 26.33 & 8.02 & 10.90 \\
\hline Significance level & $0.01^{8}$ & $0.01^{8}$ & $0.01^{8}$ & $0.01^{8}$ & $0.01^{8}$ & $0.02^{8}$ & $0.01^{8}$ \\
\hline
\end{tabular}

Legend: $\mathrm{N}=$ number of subjects; $\mathrm{df}=$ degrees of freedom; $\mathrm{W}=$ weight; $\mathrm{BMI}=$ body mass index;

$\mathrm{BFP}=$ body fat percentage; $\mathrm{TC}=$ total cholesterol; $\mathrm{LDL}=$ low-density lipoprotein;

$\mathrm{HDL}=$ high-density lipoprotein; TG = triglycerides; ${ }^{*}=$ statistically significant.

It can be observed that there is an overall statistically significant difference between the mean ranks of the related groups (data recorded at the three-time points T1, T2, and T3) for all investigated parameters. In other words, at least the distribution of one-time point is different from the other two for all investigated parameters. In order to in-deep examine where the differences actually occur, we repeatedly applied the Wilcoxon signed-rank tests as post-hoc analysis on the different combinations of related groups (T1-T2, T1-T3, and T2-T3). The analysis was conducted with a Bonferroni correction applied in a form of setting the significance level at $\mathrm{p}<0.017$ ( 0.05 divided by 3 , where 3 is the number of running tests). From Table 3 it is observed that the results are statistically significant only for W, BMI, BFP, TC, and LDL.

Table 3

RESULTS OF POST-HOC ANALYSIS USING THE WILCOXON SIGNED-RANK TESTS

\begin{tabular}{|c|c|c|c|c|c|c|c|c|}
\hline Related groups & Test statistics & W & BMI & BFP & $\mathrm{TC}$ & LDL & HDL & TG \\
\hline \multirow{2}{*}{ T1-T2 } & $\bar{Z}$ & -0.73 & -0.67 & -0.50 & $-3,75$ & -2.99 & -1.35 & -1.69 \\
\hline & Significance level & 0.46 & 0.50 & 0.61 & $0.01^{8}$ & $0.01^{8}$ & 0.17 & 0.08 \\
\hline \multirow{2}{*}{ T1-T3 } & $\mathrm{Z}$ & -3.55 & -3.54 & -2.57 & -3.94 & -3.59 & -1.56 & -1.66 \\
\hline & Significance level & $0.01^{8}$ & $0.01^{8}$ & $0.01^{8}$ & $0.01^{8}$ & $0.01^{8}$ & 0.11 & 0.09 \\
\hline \multirow{2}{*}{ T2-T3 } & $\mathrm{Z}$ & -3.21 & -3.21 & -2.37 & -3.95 & -3.72 & -0.55 & -0.78 \\
\hline & Significance level & $0.01^{8}$ & $0.01^{8}$ & $0.01^{8}$ & $0.01^{8}$ & $0.01^{8}$ & 0.58 & 0.43 \\
\hline
\end{tabular}

Legend: $\mathrm{W}=$ weight; $\mathrm{BMI}=$ body mass index; $\mathrm{BFP}=$ body fat percentage; $\mathrm{TC}=$ total cholesterol;

$\mathrm{LDL}=$ low-density lipoprotein; $\mathrm{HDL}=$ high-density lipoprotein; $\mathrm{TG}=$ triglycerides; $*=$ statistically significant at $\mathrm{p}<0.017$.

The results for W, BMI and BFP are statistically significant in the case of T1-T3 and T2-T3 comparisons and for TC and LDL in all three related groups. The changes are not very large, especially since the participants are healthy people, but enough to justify the efficiency of the intervention in improving the nutritional status and the lipid profile of the subjects. It is noticeable that the effects become important through cumulation over time, the tendency being clearer in the case of TC 
and LDL. Other authors have also shown small but significant decreases in body weight and fat mass after WBV exposure, eventually associated with exercise programs, in healthy individuals or with metabolic endocrine disorders [15, 22]. Based on the above analysis, we can propose the continuation of the research on obese subjects, considering that the success of a weight-loss program on obese people is closely linked to fat mass reduction [20].

It is important to mention that other animal studies have demonstrated metabolic effects of WBV on LDL concentrations in apolipoprotein E-deficient mice and the lack of effects on TC, TG, and HDL [23]. Also, another suggestive study mentions the beneficial impact of cycloid vibrations, produced in three perpendicular directions, with variable frequency, applied regularly for 21 days on TC and LDL cholesterol, in older women with hypercholesterolemia [24]. The catabolic effect of vibration on adipose tissue can be explained by the conversion of kinetic energy into thermal energy, under the friction forces $[24,25]$. Also, studies in mice have shown that the exposure of the body to vibration simulates the effects of exercise on metabolism [26].

A limitation of our study refers to the fact that we did not extend the analysis of the evolution of the subjects according to sex, given the relatively small size of the study group. Further, future research may also consider other categorical variables, such as gender, age of subjects, type of diet, associated morbidity, exercise exposure etc. [27].

\section{Conclusions}

The present study validated the efficiency of the WBV exposure program on improving the nutritional status and lipid metabolism of participants. Thus, the proposed therapeutic protocol had a beneficially impact on lowering the subjects' W, BMI, BFP, TC and LDL ( $\mathrm{p}$ 0.017). Our results indicated that repeated WBV exposure at diagonal stimuli, at $25 \mathrm{~Hz}$ may be a useful and non-invasive means of prophylactic intervention on healthy people, with positive effects on body composition and SLP. Therefore, the method acquires potential applications in various metabolic or nutritional disorders, and this research may be a starting point for more extensive clinical studies on various target groups of patients.

\section{References}

1. THIBAULT, R., GENTON, L., PICHARD, C., Clin Nutr, 31, no. 4, 2012, p. $435-447$.

2. BORGA, M., WEST, J., BELL, J.D. et al., J Investig Med, 66, no. 5, 2018, p. 1-9.

3. KOBAYASHI, J., MURANO, S., KAWAMURA, I. et al., J Atheroscler Thromb, 13, no. 5, 2006, p. 221-226.

4. RUBIRA, M.C., RUBIRA, A.P., RUBIRA, L.A. et al., Rev Bras Educ Fís Esporte, (São Paulo), 28, no. 4, 2014 , p. $553-560$.

5. TOWFIGHI, A., \& HILL, V. (2017). Semin Neurol, 37, no. 3, 2017, p. 237-258.

6. PLESA, CF., NICOLAE, C., SIRBU, CA., NEMES, R., PAUNESCU, A., TANTU, MM., Farmacia, 67, 2019, p. $27-33$.

7. BERI, K., Future Sci OA, 4, no. 3, 2018, FSO274.

8. TAIAR, R., BITTENCOURT, MACHADO, C.B. et al., Whole body vibrations: physical and biological effects on the human body, 1st Edition, 2018, CRC Press, Taylor \& Francis Group, NY.

9. LIN, C.I., HUANG, W.C., CHEN, W.C. et al., Metabolism, 64, no. 9, 2015, p. 1146-1156.

10. TANTU, M.M., MAN, G.M., ROGOZEA, L.M. et al., Rom J Morphol Embryol, 59, no. 3, 2018, p. 895-902.

11. TANTU, M.M., MAN, G.M., PAUNESCU, A. et al., Rev. Chim. (Bucharest), 70, no. 4, 2019, p. 1307-1310.

12. BUSE, A.M., NANEA, I.T., NICOLAE, C. et al., Rev. Chim. (Bucharest), 70, no. 5, 2019, p:1738-1743.

13. IORDACHE, PD., MATES, D., GUNNARSSON, B. et al., J Cell Mol Med. 22, no. 12, 2018, p. 6068-6076.

14. WIENECKE, E., Performance explosion in sports and anti-doping-concept: revolutionary new findings in the area of micronutrient therapy training continuity, training optimization, injury prevention through personalized micronutrients, 2011, Maidenhead: Meyer \& Meyer Sport.

15.OMIDVAR, M., ALAVINIA, S.M., CRAVEN, B.C., J Musculoskelet Neuronal Interact, 2019, Accepted article, p. 1-10, http://www. ismni. org/jmni/accepted/JMNI_19M-02-022.pdf.

16. LINTSI, M., KAARMA, H., KULL, I., Clin Physiol Funct Imaging, 24, no. 2, 2004, p. 85-90.

17. LUSZCZKI, E., SOBEK, G., BARTOSIEWICZ, A. et al., Medicina (Kaunas), 55, no. 7, 2019, p. 397.

18. KIM, H., KIM, Y., PARK, J. et al., Clin Lab, 62, no. 7, 2016, p. 1201-1208.

19. FRIEDEWALD, W.T., LEVY, R.I., FREDRICKSON, D.S. Clin Chem, 18, 1972, p. 499-502.

20. BRANCO, B.H.M., BERNUCI, M.P., MARQUES, D.C. et al., J Exerc Rehabil, 14, no. 6, 2018, p. 974-979.

21. CATAPANO, A.L., GRAHAM, I., DE BACKER, G. et al., Eur Heart J, 37, no. 39, 2016, p. 2999-3058.

22. SONG, G.E., KIM, K., LEE, D.J. et al., Korean J Fam Med, 32, no. 7, 2011, p. 399-405.

23. WU, H., ZHANG, Y., YANG, X. et al., Biomed Res Int, 2018, 4934861.

24. PIOTROWSKA, A.M., BIGOSINSKA, M., POTOK, H. et al., Menopause Rev, 17, no. 4, 2018, p. 161-167.

25. PETRESCU, I., MOHORA, C., ANANIA, F. D. et al., Mat. Plast., 53, no.4, 2016, p. 639-641.

26. MCGEE-LAWRENCE, M.E., WENGER, K.H., MISRA, S. et al., Endocrinology, 158, no. 5, 2017, p. 1160-1171.

27. CIUCUREL, C., GEORGESCU, L., ICONARU, E.I., Biomedical Signal Processing and Control, 40, 2018 , p. $156-162$.

Manuscript received: 6.11.2019 
